\title{
A AVALIAÇÃO DA APRENDIZAGEM NO ENSINO FUNDAMENTAL I: COMO O ALUNO SE PERCEBE NESTE PROCESSO?
}

\section{LEARNING ASSESSMENT IN FIRST GRADES OF ELEMENTARY SCHOOL: HOW DOES THE STUDENT SEE HIMSELF IN THIS PROCESS?}

\author{
Caroline Marangoni Gava1 \\ Zélia Medeiros Silveira ${ }^{2}$
}

\begin{abstract}
RESUMO: O texto discute a avaliação da aprendizagem sob o olhar do aluno e tem como objetivo principal: compreender a visão dos alunos do $5^{\circ}$ ano do ensino fundamental I sobre o processo de avaliação da aprendizagem, ao qual foram submetidos durante a sua escolaridade. Para que este objetivo fosse alcançado, inicialmente fez-se um estudo teórico para melhor compreender sobre o tema proposto. Em seguida realizou-se uma pesquisa de campo por meio de entrevistas semiestruturadas com oito alunos de uma escola da rede municipal de Nova Veneza/SC. Diante da análise das respostas, percebeu-se que os alunos entrevistados compreendem a avaliação basicamente como a aplicação de provas ou de outros instrumentos formais ao final de um determinado período de estudos e parecem desconhecê-la como um importante instrumento de mediação para o processo de ensino-aprendizagem. Constatou-se ainda que para grande parte destes alunos a avaliação é motivo de ansiedade e que as experiências ruins fazem parte desse processo e, geralmente, estão ligadas ao baixo desempenho obtido na aprendizagem. Eles acreditam que a avaliação contribui com a aprendizagem, pois para realizá-la é fundamental estudo e dedicação. Diante disso foi possível perceber a influência da avaliação classificatória no processo educativo desses alunos. A análise desses resultados aponta para a necessidade de reflexão das práticas pedagógicas desenvolvidas nas escolas, bem como para um maior investimento na formação dos professores que atuam na educação básica.
\end{abstract}

PALAVRAS-CHAVE: Avaliação. Processo ensino-aprendizagem.

ABSTRACT: This text discuss the learning evaluation through the students view, and it has as main objective: comprehending the students vision of the Fifth Year of elementary school about the learning evaluation process, in which they were submitted during their schooling. To achieve this objective, we initially did a theoretical study to comprehend further the proposed topic. Afterwards, we did a field research with semi-structured interviews, these applied to eight students from a municipal school of Nova Veneza, SC - Brazil. With the

\footnotetext{
${ }^{1}$ Graduada em Pedagogia da Universidade do Extremo Sul Catarinense - UNESC. zms@ unesc.net

2 Professora do Curso de Pedagogia da Universidade do Extremo Sul Catarinense - UNESC. Mestre em Educação.zms@unesc.net.

Saberes Pedagógicos, Criciúma, v. 1, n², julho/dezembro 2017.- Curso de Pedagogia- UNESC
} 


\section{SABERES PEDAGÓGICOS}

Revista do Curso de Graduação de Pedagogia - Unesc

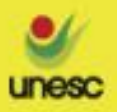

answers analyzed, we noticed the interviewed students comprehend the evaluation as an exam application or other formal instruments at the end of a specific studies period, and they seem not to know it as an important instrument of mediation to the process of teaching-learning. It was also found out that a substantial part of these students consider the evaluation an anxiety motivator, and the bad experiences are part of this process - generally, they are linked to the low performance gotten on the learning. They believe the evaluation contributes with the learning, because to do it study and dedication are essential. Accordingly, it was possible realize the influence of the classificatory evaluation in the educative process of these students. The analysis of these results points out to the necessity of reflecting the pedagogical practices developed in the schools as well as a major investment on the teachers' formation that work in the elementary school.

KEYWORDS: Evaluation. Teaching-learning process.

\section{INTRODUÇÃO}

Partindo da ideia de que o processo de ensino e aprendizagem se constitui como uma via de mão dupla e que o aluno e o professor são sujeitos ativos nesse processo, tão importante quanto o professor entender o significado da avaliação é que o aluno também o entenda.

Nesse sentido, o tema "A avaliação da aprendizagem no ensino fundamental I: como o aluno se percebe neste processo?" surgiu a partir da minha vivência como aluna durante todo o ensino básico, período em que por muitas vezes não conseguia compreender qual era o significado e a função da avaliação da aprendizagem, vendo-a somente como um sistema quantitativo de medida e que se tornava motivo de muita angústia e ansiedade.

Diante da inquietação acerca de algumas questões que envolvem o processo de avaliação do ensino e aprendizagem me dispus a pesquisar sobre o tema aqui proposto, cujo problema é: Como acontece o processo de avaliação do ensino e aprendizagem na visão de alunos do $5^{\circ}$ ano do ensino fundamental I? Para que a pesquisa fosse realizada estabeleceu-se como objetivo geral: Compreender a visão dos alunos do $5^{\circ}$ ano do ensino fundamental I sobre o processo de avaliação da aprendizagem, ao qual foram submetidos durante a sua escolaridade. Para atingir este objetivo estabeleceram-se os seguintes objetivos específicos: Analisar qual é o significado da avaliação para os alunos; Investigar as experiências positivas e negativas em relação à avaliação da sua aprendizagem;

Saberes Pedagógicos, Criciúma, v. 1, n², julho/dezembro 2017.- Curso de Pedagogia- UNESC 
Verificar como eles se preparam para serem avaliados; Identificar quais instrumentos são utilizados para avaliar a sua aprendizagem; Apontar em que medida os procedimentos avaliativos contribuem para o processo de aprendizagem.

Como procedimento metodológico realizou-se um estudo teórico sobre a avaliação da aprendizagem e uma pesquisa de campo por meio de entrevista semiestruturada com 8 (oito) alunos do $5^{\circ}$ ano do ensino fundamental I. As respostas obtidas foram transcritas pela pesquisadora e analisadas com respaldo do referencial teórico que fundamenta este trabalho.

\section{CONCEPÇÕES DE ENSINO-APRENDIZAGEM}

A prática docente é decorrente da concepção de ensino-aprendizagem do professor. Consequentemente, a avaliação como parte fundamental desse processo também acontece de acordo com tal concepção. Por essas razões, para se compreender a forma como o professor materializa o processo avaliativo em sala de aula é importante compreender a sua concepção sobre o ensino e a aprendizagem. Entre as concepções de ensino-aprendizagem destacam-se: Inatista, Comportamentalista, Construtivista e Histórico-Cultural.

$\mathrm{Na}$ concepção Inatista a ênfase está nos fatores hereditários ou nos fatores de maturação. Segundo Fontana e Cruz (1997), na perspectiva Inatista o que determina que a aprendizagem de fato aconteça é o desenvolvimento do sujeito e para que esse desenvolvimento aconteça ele depende da maturação do seu pensamento, das suas habilidades ou também do nível da sua inteligência. Nesse sentido, aquilo que o sujeito aprende não tem o poder de interferir no seu progresso, uma vez que o desenvolvimento e a maturação são tidos como aspectos mais relevantes.

Cabe ainda destacar que para Fontana e Cruz (1997) as influências do meio em que o indivíduo se encontra podem apenas tornar o seu desenvolvimento mais fácil ou mais difícil. Portanto, nesta concepção o sujeito não se desenvolve ao aprender, mas sim aprende conforme o nível de seu desenvolvimento e a sua maturação. A herança genética e as mudanças que favorecem a maturação de cada pessoa é que determinam a sua aprendizagem, e não o contrário. 
Levando-se em consideração que o sujeito é determinado por sua herança genética e o meio social pouco interfere, o processo pedagógico escolar se submete às possibilidades do indivíduo. Desse modo, o processo avaliativo se torna um ato mecânico, de verificação de seus conhecimentos. Tanto a escola quanto o professor exercem um papel passivo. Esta concepção atende aos princípios de uma avaliação classificatória.

Diferente da concepção Inatista, para a Comportamentalista o que determina as aprendizagens do sujeito são os fatores externos. Para Fontana e Cruz (1997), ao dar ênfase aos fatores externos ao sujeito, a concepção Comportamentalista destaca a importância das experiências e daquilo que cada indivíduo aprende no decorrer de sua vida para a determinação de seu comportamento e do seu desenvolvimento. Portanto, as relações que o indivíduo tem com o meio são essenciais para que ele se desenvolva, ao contrário da concepção Inatista, que dá ênfase aos fatores biológicos, ou seja, internos.

Ainda segundo Fontana e Cruz (1997), na concepção Comportamentalista o desenvolvimento é resultado da aprendizagem, que por sua vez acontece mediante a relação do sujeito com o ambiente e sua experiência, enfatizando assim a importância da influência dos fatores externos sobre os fatores internos. Considerando que os fatores externos são determinantes, a escola e professor têm o papel de modelar os comportamentos que consideram favoráveis.

Nesse sentido, o professor para ensinar precisa estimular a reprodução e a memorização. Portanto, o processo avaliativo leva em consideração os conteúdos que foram absorvidos pelos estudantes, por meio da reprodução destes. Para avaliar a aprendizagem a escola utiliza-se principalmente da prova, cujos conteúdos absorvidos pelo estudante devem ser devolvidos ao professor. Esse processo envolve basicamente a memorização e a repetição mecânica por parte dos alunos. Assim como na Inatista, caracteriza-se como uma avaliação do tipo classificatória.

Outra concepção de ensino-aprendizagem é a Construtivista, que tem como principal expoente Jean Piaget (1896 - 1980). Esta considera que o processo de aprendizagem ocorre por meio da assimilação e da acomodação. Segundo Piaget (1975), a assimilação ocorre quando o sujeito, ao se deparar com o novo conhecimento, estabelece relação com os 
conhecimentos já existentes. Portanto, no processo de assimilação não há modificação dos esquemas mentais.

Já na acomodação o sujeito incorpora novos elementos ao conhecimento existente, ou seja, modifica seus esquemas mentais, transformando as relações estabelecidas no ambiente em que vive. Nesse sentido, os elementos do meio são introduzidos em seus esquemas por meio da assimilação e da acomodação e passam a ter significado, transformando assim o pensamento e suas estruturas. Sendo assim, a assimilação e a acomodação estão ligadas uma à outra, contribuindo com o desenvolvimento intelectual do sujeito.

A equilibração é outro fator importante para o desenvolvimento. Fontana e Cruz (1997) afirmam que, para Piaget, a equilibração é inerente à vida mental e é por meio dela que o indivíduo consegue se adaptar ao meio e manter-se em equilíbrio e em processo de autorregulação. Nesse sentido, para que o desenvolvimento do sujeito aconteça depende também da equilibração.

Ainda de acordo com Fontana e Cruz (1997), na concepção de ensinoaprendizagem Construtivista o desenvolvimento do indivíduo e das suas estruturas cognitivas depende de modo essencial da equilibração e se constroem e reconstroem partindo da sua atuação no meio em que vive. Desse modo, a aprendizagem não interfere de modo significativo no desenvolvimento, uma vez que o que determina o progresso do sujeito são os avanços de suas estruturas cognitivas. A avaliação nessa perspectiva deve considerar o processo de construção do conhecimento e das possibilidades de pensamento do aluno, atendendo aos pressupostos da concepção formativa.

De modo diferente, na concepção Histórico-Cultural a ênfase é dada nas relações sociais do sujeito com o meio. Para Fontana e Cruz (1997, p. 57): "seus modos de perceber, de representar, de explicar e de atuar sobre o meio, seus sentimentos em relação ao mundo, ao outro e a si mesmo, enfim, seu funcionamento psicológico, vão se constituindo nas suas relações sociais." Portanto, o sujeito é o resultado das relações que estabelece no meio social e é influenciado pelos fatores hereditários e pelos fatores culturais presentes neste meio.

Fontana e Cruz (1997) dizem que o sujeito se desenvolve primeiro socialmente para depois desenvolver-se individualmente. Nesse sentido, a Concepção Histórico-cultural 
enfatiza a importância da mediação no desenvolvimento do indivíduo, atuando na zona de desenvolvimento proximal. Para Vigotsky (1998), a zona de desenvolvimento proximal é a distância entre aquilo que o sujeito já consegue realizar de forma independente e aquilo que é realizado com a ajuda de outra pessoa mais experiente. Sendo assim, aquilo que no momento o sujeito realiza com a ajuda de outra pessoa ele realizará mais tarde sem o auxílio de ninguém, e isso acontece por meio da mediação.

Respaldando as ideias de Vigotsky, Oliveira (1997, p. 60) diz que "interferindo constantemente na zona de desenvolvimento proximal das crianças, os adultos e as crianças mais experientes contribuem para movimentar os processos de desenvolvimento dos membros imaturos da cultura." Nesse sentido, as relações do sujeito com o meio e com os outros indivíduos são essenciais, contribuindo assim para o seu desenvolvimento.

Vale destacar que na zona de desenvolvimento proximal a mediação acontece por meio de instrumentos e signos. Segundo Oliveira (1997), o instrumento é algo externo, ou seja, ele é utilizado pelo indivíduo para alterar os objetos e controlar a natureza. Já os signos são internos ao sujeito e, ao contrário dos instrumentos, que auxiliam no que é tangível, eles dão subsídios aos processos psicológicos do indivíduo. Portanto, a mediação torna-se um processo fundamental no desenvolvimento social e individual do sujeito.

Cabe ainda destacar que, para Vigotsky (1998, p. 117), “[...] o aprendizado desperta vários processos internos de desenvolvimento, que são capazes de operar somente quando a criança interage com pessoas em seu ambiente e quando em cooperação com seus companheiros." Sendo assim, nesta concepção, o aprendizado e o desenvolvimento estão imbricados, sendo que o desenvolvimento acontece mediante a aprendizagem, que por sua vez acontece na relação do indivíduo com os instrumentos, signos e com o outro.

Dando destaque à importância da mediação no processo ensino-aprendizagem, o processo avaliativo deve cumprir a mesma função, ou seja, deve intervir na apropriação dos conhecimentos pelos estudantes, ajudando-os a formular elaborações cada vez mais complexas. Desse modo, a concepção de avaliação é eminentemente formativa.

Compreender essas teorias é importante, visto que tais concepções influenciam de forma implícita ou explícita na prática pedagógica, podendo determinar o encaminhamento do 
processo de ensino e aprendizagem e, consequentemente, também a avaliação, uma vez que esta é parte indispensável desse processo.

\section{CONCEPÇÕES E FUNÇÕES DA AVALIAÇÃO DA APRENDIZAGEM}

A avaliação está presente em nossa vida, sobretudo, no processo de ensino e aprendizagem nas escolas. A forma como a avaliação acontece pode denunciar os significados que o professor atribui a esta, podendo variar de acordo com a concepção que ele tem de avaliação. Portanto, para compreender esses significados é importante compreender também as concepções de avaliação que orientam os processos pedagógicos desenvolvidos nas escolas. Entre essas concepções estão a classificatória e a formativa.

A avaliação classificatória baseia-se na memorização e na reprodução de conteúdos, promovendo os alunos por meio de notas, limitando-se apenas ao ato de verificar o rendimento do aluno ao final de um determinado período. Segundo Luckesi (2009, p. 92):

\footnotetext{
A dinâmica do ato de verificar encerra-se com a obtenção do dado ou informação que se busca, isto é, 'vê-se' ou 'não se vê' alguma coisa. E... Pronto! Por si, a verificação não implica que o sujeito retire dela conseqüências novas e significativas.
}

Esta prática não dá ênfase aos meios, mas sim ao fim, não levando em conta o processo de ensino e aprendizagem como um todo, valorizando somente o resultado final. Hoffmann (1991) diz que quando a avaliação é praticada com a função classificatória o conhecimento é fragmentado e descontínuo. Sendo assim, a avaliação classificatória não contribui para que o conhecimento de fato possa ser garantido ao educando.

Conforme Luckesi (2009), a avaliação classificatória é autoritária e paralisa o desenvolvimento, não oportunizando a aproximação de todos ao saber elaborado. Ademais, coloca a responsabilidade pelo fracasso escolar no aluno, uma vez que nessa concepção a avaliação se dá para verificar somente o rendimento do aluno e não do processo de ensino e aprendizagem como um todo. Ainda segundo Luckesi (2009), esta é uma prática seletiva, pois nela uma parte dos alunos é aceita e a outra é excluída. Portanto, a avaliação se torna um 
instrumento de segregação e exclusão cujo objetivo é o de quantificar as aprendizagens dos alunos, classificando-os quanto ao seu rendimento.

Contrária à concepção de avaliação classificatória está a concepção de avaliação formativa, também conhecida como avaliação dialógica, processual, emancipatória e mediadora, que vê o aluno como parte indispensável no processo de ensino e aprendizagem. Nesse sentido, para Hoffmann (1991), a avaliação deixa de acontecer ao final do processo de ensino e passa a ser concebida como a busca do entendimento das possibilidades e avanços do aluno, bem como das suas dificuldades, transformando-se em novas oportunidades para que o conhecimento aconteça. Sendo assim, nesta concepção a avaliação é compreendida como um importante instrumento de mediação para que a aprendizagem ocorra de forma significativa.

Muito mais do que medir os conhecimentos dos alunos ou classificá-los, a avaliação formativa também contribui para que o professor reflita suas práticas. Villas Boas (2006, p. 77) diz que "contrariamente à avaliação classificatória, a formativa promove a aprendizagem do aluno e do professor, e o desenvolvimento da escola, sendo, portanto, aliada de todos." Desse modo, a avaliação ganha um sentido de inclusão, de valorização do processo de ensino e aprendizagem e se desprende do autoritarismo, uma vez que aluno e professor são beneficiados. Esta concepção de avaliação valoriza o aluno e o compreende como parte integrante de todo o processo.

Conforme Hoffmann (1991), a avaliação torna-se ação por meio da reflexão do professor sobre si mesmo e sobre o educando e o seu conhecimento. Sendo assim, a avaliação não está a favor somente do professor, mas também do aluno, tornando-se um instrumento mediador do ensino e aprendizagem, possibilitando reflexões acerca do trabalho de ambas as partes, buscando sempre superar as dificuldades.

A avaliação formativa não acontece somente ao final de um determinado período, mas sim durante todo o processo de ensino e aprendizagem, possibilitando uma constante reflexão sobre as práticas dos educadores e dos educandos, exercendo função diagnóstica, formativa e somativa.

A função "diagnóstica" visa identificar as aprendizagens do aluno e saber quais as suas dificuldades. Luckesi (2009) diz que, como diagnóstica, a avaliação é um momento para investigar em que estágio se está e qual é a distância para alcançar o ponto a ser atingido. 


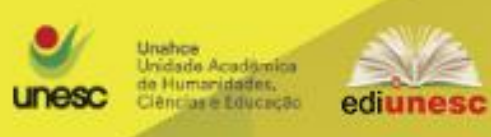

Portanto, como diagnóstica, a avaliação cumpre a função de diagnosticar a aprendizagem, buscando sanar as dificuldades para que se possa prosseguir no processo de ensino e aprendizagem.

Outra função é a "formativa", que se constitui em um processo contínuo que acontece em todos os momentos do processo de ensino e aprendizagem. Villas Boas (2006) diz que a avaliação também cumpre a função formativa e é por meio dela que o professor analisa a evolução dos alunos de forma frequente, verificando o que aprenderam ou não, podendo assim reorganizar o seu trabalho.

Sendo assim, a função formativa contribui para que se possa qualificar o processo de ensino e aprendizagem para ambas as partes. Para Chueiri (2008), na função formativa interessa todo o processo que o aluno percorre para que se aproprie do conhecimento. Nesse sentido, possibilita a reflexão dos caminhos percorridos durante o processo de ensino e aprendizagem, servindo assim como uma bússola orientadora.

Cabe ainda destacar que para Villas Boas (2006) a função formativa é aliada de todos, pois favorece tanto a aprendizagem do aluno quanto a do professor e também contribui para o progresso escolar. Portanto, além de contribuir para a aprendizagem do aluno essa função também permite ao professor se autoavaliar, avaliar o seu plano e a sua metodologia, podendo assim construir e reconstruir a sua prática docente para que o processo de ensino e aprendizagem seja garantido.

Já a função "somativa" tem por objetivo verificar o rendimento do aluno ao final de um determinado período de estudos. Segundo Chueiri (2008), sua função é, ao final de determinado período, verificar o conhecimento adquirido pelo aluno. Sendo assim, a função somativa pode materializar-se em notas e classificar o aluno de acordo com o seu nível de aprendizagem e desempenho. Contudo, é importante salientar que essa função se faz necessária no processo avaliativo na medida em que, aliada às demais funções, permite ao professor identificar o que de fato o aluno compreendeu sobre determinado conteúdo. Libâneo (1994, p. 199) diz que “o entendimento correto da avaliação consiste em considerar a relação mútua entre os aspectos quantitativos e qualitativos." Portanto, a função somativa é essencial ao processo avaliativo quando praticada junto à função diagnóstica e formativa.

Saberes Pedagógicos, Criciúma, v. 1, n², julho/dezembro 2017.- Curso de Pedagogia- UNESC 
Como é possível perceber, a avaliação é muito importante no trabalho pedagógico e possibilita a reflexão de todos os envolvidos no processo de ensino e aprendizagem. Para que esta aconteça de forma efetiva é necessário que essas três funções estejam imbricadas, garantido assim a qualidade do processo de apropriação do conhecimento.

\section{PROCEDIMENTOS E INSTRUMENTOS AVALIATIVOS DO PROCESSO ENSINO - APRENDIZAGEM}

O processo de avaliação da aprendizagem dispõe de procedimentos e instrumentos variados, podendo esses ser formais ou informais, variando também de acordo com a concepção que se tem de avaliação. Sobre a avaliação formal e informal Libâneo (1994, p. 205) diz que:

\footnotetext{
As verificações por meio de provas escritas dissertativas, de questões objetivas ou práticas são de caráter mais formal. Os procedimentos que visam o acompanhamento dos alunos nas várias situações diárias, como a observação e a entrevista, são de caráter menos formal, embora de grande valor na compreensão e apreensão da real aprendizagem do aluno.
}

Como visto, a "avaliação formal" é o acompanhamento sistemático do desenvolvimento do aluno, ocorrendo de maneira ordenada e pontual. Nesse caso o professor deve recorrer de diferentes instrumentos avaliativos para favorecer a todos. Esse procedimento avaliativo é o que mais se evidencia nas escolas e muitas vezes é evidenciado no final de um determinado período. Segundo Luckesi (2009), na organização do processo avaliativo os professores elaboram provas ou algum outro instrumento para que os alunos demonstrem o seu entendimento sobre os conteúdos ensinados.

Vale destacar que os procedimentos formais também fazem parte da avaliação formativa e quando elaborados de forma adequada são de suma importância, uma vez que por meio da avaliação formal o professor consegue de fato identificar aquilo que o aluno se apropriou sobre determinado conteúdo. Para Libâneo (1994), os instrumentos formais de verificação são essenciais para obter informações fidedignas sobre o desempenho do aluno e averiguar como está sendo realizado o trabalho pedagógico do professor. Nesse sentido, os procedimentos formais são indispensáveis ao processo avaliativo.

Saberes Pedagógicos, Criciúma, v. 1, n², julho/dezembro 2017.- Curso de Pedagogia- UNESC 
De modo diferente dos procedimentos formais, a "avaliação informal" permite ao professor acompanhar o desenvolvimento constante do aluno e também as suas possíveis dificuldades. Para Villas Boas (2006), no momento em que o aluno mostra ao professor alguma atividade, quando lhe pede ajuda ou até mesmo quando o professor observa o aluno trabalhar em sala de aula ocorre uma prática avaliativa, ou seja, há a oportunidade de acompanhar o desenvolvimento do aluno. Portanto, como informal a avaliação pode acontecer por meio de observação, registros, conversas e outros instrumentos que permitam ao professor identificar os avanços dos alunos no decorrer do processo de aprendizado.

Ainda de acordo com Villas Boas (2006), a avaliação informal muitas vezes não é planejada, por isso nem sempre os alunos sabem que estão sendo avaliados, e para isso é preciso que o professor haja com postura ética. Sendo assim, quando acontece de modo informal, a avaliação se torna mais maleável e por isso deve ser praticada com seriedade e respeito à individualidade de cada aluno, pois pode trabalhar a favor da inclusão e também da exclusão, uma vez que o professor pode não ter parâmetros para avaliar e acaba baseando-se somente no que julgar certo.

No processo de avaliação formal e informal o professor pode utilizar-se de diferentes instrumentos avaliativos. Entre eles encontram-se aqueles que oportunizam ao aluno refletir sobre o seu aprendizado e suas possibilidades e dificuldades.

A avaliação por colegas é um desses instrumentos, pois permite aos alunos analisar as suas produções e a de seus colegas. Para Villas Boas (2006, p. 85), "esse tipo de avaliação permite a participação dos alunos e aumenta a comunicação entre eles e o professor, sobre sua aprendizagem." Sendo assim, a avaliação feita por colegas proporciona o estreitamento da relação entre aluno e professor e também permite ao aluno avaliar o trabalho do colega e o seu próprio trabalho, levando-o à autoavaliação, que por sua vez é outro instrumento importante de avaliação.

A autoavaliação permite ao aluno refletir sobre as atividades por ele realizadas. Villas Boas (2006) diz que a autoavaliação é um importante processo em que o aluno analisa as suas próprias atividades, apontando seu entendimento e definindo ações futuras, possibilitando assim o progresso de sua aprendizagem. Portanto, contrariamente à atribuição de notas, a autoavaliação possibilita a formação de um sujeito crítico e emancipado, capaz de 
refletir sobre suas dificuldades e seus progressos no decorrer do processo de ensino e aprendizagem.

Como visto, muitos são os procedimentos e os instrumentos avaliativos. Luckesi (2009) diz que para reunir dados sobre a aprendizagem dos alunos os professores fazem uso de instrumentos variados, que vão desde a observação até testes elaborados com alguns critérios. Sendo assim, a avaliação recorre a instrumentos diversos para que seja efetivada, podendo ser formais ou informais.

Tanto os instrumentos formais quanto os instrumentos informais de avaliação possibilitam ao professor uma melhor análise do progresso do educando. Para Villas Boas (2006, p. 83):

O professor atento, interessado na aprendizagem do seu aluno e investigador da realidade pedagógica procurará usar todas as informações advindas da informalidade para cruzá-las com os resultados da avaliação formal e, assim, compor a sua compreensão sobre o desenvolvimento de cada aluno.

Muitas são as possibilidades para que a avaliação aconteça e o uso de determinados procedimentos e instrumentos estão ligados à concepção que o professor tem sobre a avaliação, podendo ser evidenciada de forma implícita ou explícita em sua prática docente. Portanto, de acordo com a concepção de avaliação do professor ele poderá priorizar determinados instrumentos e procedimentos avaliativos no decorrer do processo de ensino e aprendizagem.

\section{METODOLOGIA, APRESENTAÇÃo E ANÁLISE DE DADOS}

O presente trabalho se constitui em uma pesquisa de campo do tipo exploratória, com abordagem qualitativa. Segundo Gil (1991), o objetivo dessas pesquisas é possibilitar a proximidade com o problema, tornando-o explícito e aperfeiçoando determinadas ideias ou descobertas.

Inicialmente, para fundamentar as discussões aqui realizadas fez-se um estudo teórico para melhor compreender sobre o tema proposto. A partir do estudo teórico realizouse uma pesquisa de campo por meio de entrevistas semiestruturadas com alunos de uma

Saberes Pedagógicos, Criciúma, v. 1, n², julho/dezembro 2017.- Curso de Pedagogia- UNESC 
escola pública municipal situada no município de Nova Veneza/SC.

A amostra foi intencional e foram entrevistados oito alunos, entre estes 5 (cinco) meninos e 3 (três) meninas do $5^{\circ}$ ano do ensino fundamental I, que por razões éticas serão representados por nomes fictícios.

Seis desses alunos foram indicados pela diretora da instituição por apresentarem bom desempenho e dois foram escolhidos por esta pesquisadora pelo baixo nível de aprendizagem para que se pudesse perceber se o rendimento escolar influencia na visão que estes alunos possuem sobre a avaliação da sua aprendizagem. O número desigual justifica-se por não haver mais alunos com baixo nível de aprendizagem na turma do $5^{\circ}$ ano do ensino fundamental I na instituição. Por essas razões os alunos indicados pela diretora serão identificados como Joana, Maria, Ana, Pedro, Mário e José e os alunos indicados pela pesquisadora serão identificados como Paulo e Francisco.

Os alunos se mostraram muito receptivos e abertos para responder as questões propostas. No primeiro momento das entrevistas ficaram um pouco inseguros para falar sobre a avaliação da aprendizagem, porém, iam se sentindo mais à vontade no decorrer do processo.

Os dados coletados na pesquisa de campo foram agrupados pelas questões da entrevista e serão apresentados seguidos da análise teórica.

A primeira questão da entrevista indagou " $O$ que os alunos compreendiam por avaliação e para que serve a mesma". Nesse quesito obtivemos as seguintes respostas: Joana, José, Ana, Paulo e Francisco acreditam que a avaliação é principalmente uma prova, que serve para ter nota e para ver o que aprenderam sobre o conteúdo.

Já Maria, Mário e Pedro acreditam que a avaliação é uma forma de saber o que o aluno entendeu sobre o conteúdo já estudado. Para eles a avaliação serve para testar o conhecimento e ver se entenderam a matéria.

Ao analisar as respostas percebe-se que as ideias dos alunos sobre a avaliação remetem a uma concepção classificatória. Além disso, os alunos veem a avaliação apenas como um ato mecânico e, na maioria dos casos, cobrado por meio de prova. Fica claro que a avaliação serve apenas para verificar os conhecimentos adquiridos pelos alunos sobre determinado conteúdo. Segundo Luckesi (2009), o ato de verificar acaba quando se obtém a 
informação procurada. Portanto, o que vale é o resultado final e não o processo de aprendizagem como um todo.

É evidente que para os alunos somente eles mesmos são passíveis de serem avaliados. Eles não conseguem ver na avaliação uma possibilidade de planejamento, organização e autoavaliação da prática pedagógica.

De modo diferente, a avaliação formativa é concebida por Hoffmann (1991), como aquela que busca compreender e valorizar as possibilidades e avanços do aluno, identificando suas dificuldades para transformá-las em novas oportunidades de aprendizagem. Nesse sentido a avaliação é, portanto, um importante instrumento de mediação dos processos pedagógicos de sala de aula.

A próxima questão abordou sobre "Quais instrumentos são utilizados na avaliação da aprendizagem”. Diante dessa questão as respostas foram unânimes: Todos os alunos enfatizaram a prova como instrumento de avaliação. $\mathrm{O}$ trabalho de grupo e a pesquisa também aparecem nas falas dos entrevistados. Porém, Francisco, Joana e Pedro também destacaram a tarefa no caderno valendo nota como um instrumento avaliativo.

Tais respostas indicam que para avaliar a aprendizagem dos alunos a professora faz uso com frequência de vários instrumentos formais de avaliação.

Tendo como referência os autores estudados, os instrumentos e procedimentos formais de avaliação, quando bem elaborados, são muito importantes e indispensáveis ao processo avaliativo. Porém, o professor pode utilizar-se tanto dos instrumentos e procedimentos formais, quanto dos informais para melhor acompanhar o progresso dos seus alunos. Villas Boas (2006) diz que, o professor deve ficar atento ao processo de ensino e aprendizagem buscando relacionar todas as informações obtidas na informalidade com os resultados da avaliação formal.

Em momento algum os instrumentos de avaliação informal aparecem nas falas dos entrevistados e isso dá indícios de que eles não reconhecem esses instrumentos como parte do processo de avaliação da aprendizagem. Além disso, as falas dos alunos sinalizam uma prática pedagógica com resquícios classificatórios.

A concepção classificatória fica ainda mais evidente quando os alunos foram questionados sobre "Como acontece e em que momento acontece a avaliação da 
aprendizagem". Nesta questão as respostas também foram unânimes: todos os alunos responderam que a professora apresenta o conteúdo e uma ou duas semanas depois ela dá a prova ou o trabalho para avaliar o que aprenderam sobre determinado assunto. Porém, José e Maria relataram que às vezes a professora pede para que pesquisem sobre o conteúdo quando ela ainda está apresentando o mesmo.

Diante de tais respostas percebe-se que a avaliação, de modo geral, costuma acontecer somente no final de um determinado período de estudos, cumprindo apenas a função somativa, cujo objetivo, segundo Chueiri $(2008$, p. 58) "[...] ao final de uma unidade de estudos, semestre ou ano letivo, é a de verificar se houve aquisição de conhecimento". A função somativa é de suma importância para o processo avaliativo, pois permite ao professor identificar aquilo que o aluno se apropriou, porém, a avaliação deve cumprir também a função diagnóstica e formativa, acontecendo em todos os momentos do processo de ensinoaprendizagem, possibilitando ao professor avaliar o aluno e também avaliar e reorganizar a sua prática quando necessário, contribuindo assim com todos os envolvidos nesse processo.

A questão seguinte indagou "Como os alunos se preparam para serem avaliados e se a avaliação contribui para o processo de aprendizagem".

Sobre isso, Joana, Ana, Maria, Pedro, Mário e José alegam que prestam atenção nas aulas. Além disso, estudam em casa as perguntas e respostas e o conteúdo já visto em sala de aula geralmente um dia antes da avaliação e muitas vezes contam com a ajuda da mãe e dos irmãos para isso. Paulo e Francisco alegam não estudar e dizem que têm dificuldade para se concentrar.

Sobre a contribuição da avaliação para o processo ensino-aprendizagem, todos os entrevistados responderam afirmativamente. Ana, Maria, Francisco e Mário acreditam que a avaliação ajuda a entender o conteúdo, uma vez que é preciso estudar para realizá-la.

Pedro acredita que a avaliação contribui para ver se os alunos estão "espertos" no conteúdo, contribuindo assim para a aprendizagem. Joana, José e Paulo acreditam que a avaliação contribui para a aprendizagem, pois para realizá-la é preciso estudar e se não houvesse avaliação os alunos não estudariam. Vale destacar que os alunos Mário e Paulo também acreditam que a avaliação contribui para a aprendizagem, uma vez que também serve para "passar de ano".

Saberes Pedagógicos, Criciúma, v. 1, n² , julho/dezembro 2017.- Curso de Pedagogia- UNESC 
Mais uma vez as falas dos alunos remetem a uma concepção de avaliação classificatória, pois acreditam que esta contribui com a aprendizagem, uma vez que serve para “passar de ano" e que é preciso estudar para realizá-la. Mas será que essas são as únicas contribuições da avaliação para a aprendizagem?

Do ponto de vista da concepção de avaliação formativa esse processo vai muito além. Muito mais do que contribuir para "passar de ano" ou para que os alunos estudem a avaliação, também possibilita tanto ao professor quanto ao aluno identificar as dificuldades, possibilidades e avanços durante o processo de aprendizagem. Também contribui com o professor na medida em que por meio da avaliação o mesmo pode refletir, planejar, construir e reconstruir sua prática sempre que necessário.

Para Villas Boas (2006), a avaliação formativa contribui com todos os envolvidos no processo educativo, pois promove tanto a aprendizagem do aluno quanto a do professor, contribuindo também com o progresso da escola. Portanto, diante das falas dos alunos percebe-se que a avaliação formativa não se faz presente no processo de ensinoaprendizagem.

A última questão abordou "Como os alunos se sentem ao serem avaliados e quais as suas experiências com a avaliação da aprendizagem”. Diante dessa indagação obtivemos as seguintes respostas: Mário diz se sentir tranquilo, uma vez que sempre estuda e se prepara para ser avaliado. Ana fica nervosa quando não estuda ou não entende bem o conteúdo. Porém, quando entende o conteúdo e se prepara para a avaliação se sente segura. Já Paulo, Francisco, José, Joana, Maria e Pedro demonstram preocupação com as notas em suas falas. Eles se dizem ansiosos para saber o resultado enquanto são avaliados.

Quando perguntados sobre suas experiências com a avaliação todos os alunos, exceto Mário, relataram já ter tido experiências "ruins" e isso se deu por conta do baixo rendimento na avaliação. Vale ainda ressaltar que para Maria as experiências ruins se dão pelo fato de ter medo de desapontar seus pais quando tira "nota baixa".

As respostas analisadas indicam que, de modo geral, os alunos se sentem ansiosos no momento da avaliação e fica explícita a preocupação com a nota. As experiências ruins também fazem ou já fizeram parte do processo avaliativo para a maioria dos entrevistados e normalmente estão ligadas ao desempenho deles na avaliação.

Saberes Pedagógicos, Criciúma, v. 1, n², julho/dezembro 2017.- Curso de Pedagogia- UNESC 
Diante disso, percebe-se a forte influência da avaliação classificatória no processo de ensino-aprendizagem para os alunos, uma vez que demonstram muita preocupação com as notas. Vale salientar que a ansiedade e o medo de ser avaliado é uma questão cultural que vem se perpetuando ao longo dos anos por conta da predominância da avaliação classificatória no processo de ensino-aprendizagem nas escolas e isso fica evidente quando os entrevistados revelam de forma implícita a preocupação dos pais ou responsáveis com relação a isso ao falarem do "castigo".

Cabe ainda destacar que se faz necessário relativizar as respostas dos alunos, uma vez que o processo avaliativo nas escolas, historicamente, desenvolve o "medo" de ser avaliado. Nesse sentido, apesar da prática avaliativa desenvolvida pela professora dos alunos pesquisados, eles já trazem consigo essa cultura.

\section{CONCLUSÃO}

Neste trabalho discutiu-se sobre a avaliação da aprendizagem e a visão de alunos do $5^{\circ}$ ano do ensino fundamental. Por meio da análise realizada o que se observa é que, de modo geral, os alunos compreendem a avaliação como aplicação de provas, atribuindo a ela a função de verificar se dominam os conteúdos trabalhados em sala de aula ao final de um determinado período de estudos.

Identificou-se, por meio da análise, que a avaliação da aprendizagem costuma acontecer por meio de procedimentos e instrumentos formais, uma vez que em momento algum em suas falas os entrevistados mencionaram os instrumentos informais de avaliação. Isso pode indicar que eles não reconhecem esses instrumentos como parte integrante do processo avaliativo. Além disso, verificou-se que, para realizar a avaliação, tanto quanto prestar atenção nas aulas os alunos também se preparam estudando em casa, contando muitas vezes com o auxílio dos familiares para melhor compreender sobre o conteúdo em questão.

Ao investigar as experiências em relação à avaliação percebeu-se que é motivo de ansiedade e insegurança, que de modo geral são causadas devido à preocupação com a nota. Constatou-se ainda que para grande parte dos alunos as experiências ruins se fazem presentes no processo de avaliação da aprendizagem e geralmente são consequências do baixo 
desempenho obtido.

Percebeu-se também que para os alunos a avaliação contribui com a aprendizagem na medida em que se faz necessário estudar para realizá-la. Eles não reconhecem as inúmeras possibilidades que a prova, quando bem elaborada, pode oferecer para que o processo de ensino e aprendizagem ocorra de maneira eficaz e seja garantido a todos.

Diante disso conclui-se que a avaliação classificatória vem se perpetuando e ainda se faz muito presente no processo educativo. Os alunos entrevistados sinalizam desconhecer a avaliação como um importante instrumento de mediação para identificar as suas possibilidades e os seus avanços.

Cabe destacar que de modo geral não houve diferenças nas respostas dos alunos com bom desempenho e dos alunos com baixo nível de aprendizagem sobre a avaliação. Isso revela indícios de que, independente do desempenho escolar, a avaliação é vista pelo aluno como um instrumento de verificação e carrega consigo a cultura do medo, que, por sua vez, é consequência da predominância da avaliação classificatória nas escolas.

Desse modo se faz necessária a reflexão das práticas pedagógicas desenvolvidas nas escolas e também um maior investimento na formação docente. É essencial que tanto o professor quanto os alunos possam compreender a avaliação no seu amplo sentido para que o ensino e a aprendizagem sejam assegurados e para que de fato aconteçam de forma significativa, uma vez que a avaliação é parte fundamental desse processo.

Minha pretensão com esta pesquisa não é dar o assunto por encerrado, mas sim abrir caminhos para que se possa refletir a avaliação do ponto de vista de todos os envolvidos no processo de ensino e aprendizagem.

\section{REFERÊNCIAS:}

CHUEIRI, Mary Stela Ferreira. Concepções sobre a Avaliação Escolar. Estudos em Avaliação Educacional, v. 19, n. 39, p. 49-64, jan. / abr. 2008. Disponível em: http://publicacoes.fcc.org.br/ojs/index.php/eae/article/view/2469/2423. Acesso em 22 de maio de 2016.

FONTANA, Roseli; CRUZ, Nazaré. Psicologia e trabalho pedagógico. São Paulo: Atual, 1997. $232 \mathrm{p}$. 
GIL, Antonio Carlos. Como elaborar projetos de pesquisa. 3. ed. São Paulo: Atlas, 1991. $159 \mathrm{p}$.

HOFFMANN, Jussara Maria Lerch. Avaliação: mito e desafio: uma perspectiva construtivista. Porto Alegre: Mediação, 1991. 128 p.

LIBÂNEO, José Carlos. Didática. São Paulo: Cortez, 1994. 263 p.

LUCKESI, Cipriano C. Avaliação da aprendizagem escolar: estudos e proposições. 20.ed. São Paulo: Cortez, 2009. 180 p.

OLIVEIRA, Marta Kohl de. Vygotsky: aprendizado e desenvolvimento, um processo sócio histórico. 4. ed. São Paulo: Scipione, 1997. 111p. il.

PIAGET, Jean. A construção do real na criança. Tradução de Álvaro Cabral. 2. ed. Rio de Janeiro: Zahar; Brasília, INL, 1975. 360 p.

VILLAS BOAS, Benigna Maria de Freitas. Avaliação formativa e formação de professores: ainda um desafio. Linhas críticas, Brasília, v.12, n. 22, p. 75-90, jan. / jun. 2006. Disponível em: http://periodicos.unb.br/index.php/linhascriticas/article/viewArticle/1684. Acesso em: 17 de maio de 2016.

VIGOTSKY, Lev Semenovich. A formação social da mente: o desenvolvimento dos processos psicológicos superiores. Tradução de José Cipolla neto; Luís Silveira Menna Barret; Solange Castro Afeche. 6. ed. São Paulo: Martins Fontes, 1998. 191 p. 